\title{
A NEW TYPE OF ENTOMOLOGICAL KELLING-BOTTLE.
}

\author{
By Malcolm E. MacGregor,
}

\section{Wellcome Field Laboratory, Surrey, Wellcome Bureau of Scientific Research.}

The "cyanide bottle" is never a very attractive part of the entomologist's equipment. When made up in the old way, i.e., plaster of Paris poured over lumps of solid potassium cyanide and the plaster then allowed to set, the contrivance has an attractive appearance, but is an abomination to use, especially if small insects are being dealt with. The large amount of water utilised in making up the plaster of Paris can never be dried out properly, and the potassium cyanide being deliquescent to some extent the presence of moisture is unavoidable. Moreover the cyanide soon decomposes and turns brown, imparting its colour to the plaster and forming an ugly-looking mass on which small insects, are not contrasted and may be easily overlooked and lost.

The newer method of making up the killing-bottle by powdering the cyanide and mixing this with about an equal weight of powdered borax, compressing the mass at the bottom of the bottle, and afterwards pouring over it a small amount of plaster just sufficient to secure the powders, is a distinct improvement in so far as the approach to anhydrous conditions is concerned and the more rapid liberation of $\mathrm{HCN}$ gas. However, the mass decomposes more rapidly with the addition of the borax, and the unfortunate brown coloration is accentuated.

There are too the methods that depend on fixing the potassium cyanide in the cork instead of in the bottle, which are certainly improvements in that the insects are left lying on the glass, against which they can be easily seen ; but with this method the cyanide is not in a very safe situation, and furthermore cannot so rapidly evolve as much HCN gas as cyanide that is distributed over the bottom of the bottle.

In addition to the faults peculiar to whatever method is employed in making up the cyanide killing-bottle there are the following disadvantages in the use of cyanide :-(1) the bottle is a potential danger to the ignorant if not properly looked after, owing to the highly poisonous nature of potassium cyanide ; (2) if the bottle is accidentally broken, cases of poisoning may result unless every scrap of the cyanide and plaster is collected and destroyed; (3) the killing power of the preparation speedily weakens if the bottle is constantly used; (4) insects recover more often from HCN gas in weak concentration than they do from concentrated chloroform vapour; (5) when the cyanide bottle is exhausted it is preferable to throw the whole thing away (unless the bottle is of the type where the cyanide is secured in the cork) rather than to attempt to chip out the hard plaster to renew the apparatus, and a new killing bottle has therefore to be obtained.

On the strength of these objections I have for several years preferred to use chloroform as an insect poison, utilising chloroform-saturated rubber in place of cyanide. The method is ideal as far as its action is concerned, but the one great drawback has been the rapid evaporation of the chloroform and the constant addition of the fluid that has been necessary. 
In order to have a killing-bottle which will have the great advantage of chloroform as the poison, the bottle described below is now used. It can be made from ordinary laboratory material, unless a very large-mouthed bottle is required.

Select an ordinary "boiling-tube" (large form of test-tube), and a large rubber cork which will just slide down the inside of the tube, màking rather a tight fit. Bore a hole in the centre of the cork so that a small piece of glass-tubing (internal diameter, 2 to $3 \mathrm{~mm}$.) can be forced through. The glass-tubing should be of such a size that it projects about $\frac{3}{4}$ inch on one side of the cork, and about $\frac{1}{4}$ inch on the other.

Now slide the cork into the boiling-tube so that the $\frac{3}{4}$ inch length of glass tubing projects towards the bottom of the boiling-tube, and force it down until the end of the tubing touches the bottom of the tube. If the rubber cork is a tight fit

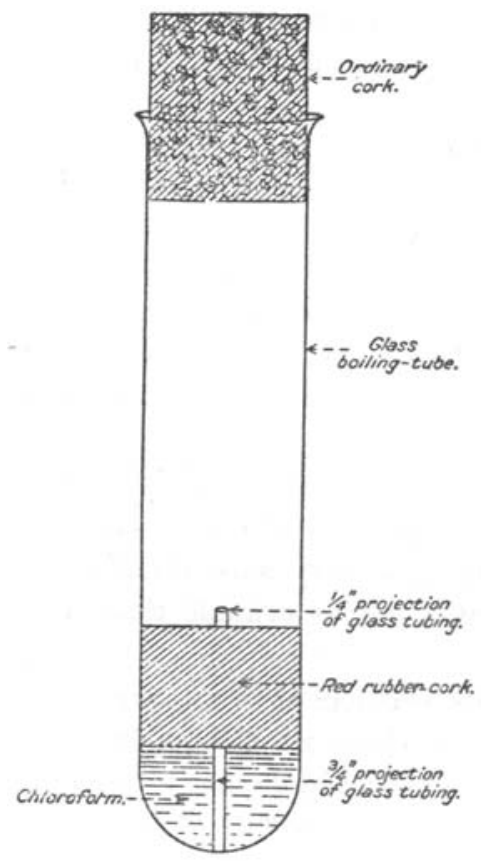

Fig. 1. A chloroform killing-bottle.

(as it should be) moisten the cork slightly with water and press it down the boilingtube by the aid of the open end of a small test-tube. Warm the apparatus so as to drive off any moisture that may remain, and when dry it may be charged with chloroform. This is accomplished as follows:-Pour into the boiling-tube sufficient chloroform to stand about 2 inches above the upper surface of the rubber cork, and then carefully warm the air-space below the cork over a spirit-lamp. The air will be partly driven out by expansion. Remove the tube from the flame and as the space cools the chloroform will run in to fill the partial vacuum. Then again heat the bottom of the tube until the chloroform within boils gently, and all the air is driven out by the chloroform vapour. On cooling once more the space will this time be completely filled with chloroform. Now invert the tube and 
pour out the surplus chloroform from the upper surface of the cork. None of the chloroform in the space below will escape, owing to the air pressure at the upper open end of the glass tubing. Gently warm the sides of the tube above the cork to drive off any remnants of liquid chloroform, and when an ordinary cork has been fitted, we have an apparatus similar to that shown in fig. 1.

Although pure rubber is soluble in chloroform, it will be found that the compound from which the rubber corks (red variaty) are made, swells when in contact with chloroform but will not dissolve.

The following are the advantages of the apparatus:-(1) A high concentration of chloroform vapour is always available; (2) if the tube is accidentally broken there is no danger of poisoning; (3) 5 cc. of chloroform is sufficient for a week's continuous use, and the tube is therefore exceedingly economical.

Care should, however, be taken that the lower end of the tube containing the chloroform be not unduly heated by the hand, otherwise gaseous pressure will force the liquid up the central glass tubing. Should this occur at any time it is only necessary to shake out the few drops of liquid at the upper end of the cork, and blow into the tube to dry the cork surface. If the tube is inverted, no amount of overheating will do more harm than to dissipate the chloroform to some extent, and for this reason it should be carried in this position. The open lower end of the glass tubing then stands above the surface of the liquid chloroform, and the apparatus is "sealed." 